\title{
ANALISIS CAPITAL BUDGETING SEBAGAI ALAT PENGAMBILAN KEPUTUSAN INVESTASI: Studi Kasus
}

\author{
${ }^{1}$ Ananda Setiawan, ${ }^{2}$ Risa Alkurnia , ${ }^{3}$ Andika Puspita Sari \\ 1,2,3 Program Studi Teknik Industri, Universitas Sebelas Maret \\ e-mail: Anandasetiawan.blogku@gmail.com
}

\begin{abstract}
A good investment decision analysis has to go through to find out the work done will benefit or not. To avoid the losses that investors received, then investors should know the proposed investment with longterm risks will be accepted. The purpose of this research is to analyze the feasibility of investment of fixed assets in the form of replacement of fixed assets fixed assets the old with new in the MSMes Serabi in Surakarta, Central Java by using techniques of Capital Budgeting. This research method is the method of the description with quantitative approach. Data analysis using the latest financial reports to count ARR, PP, NPV, and PI. Data analysis of the results ARR $126.6 \%>20 \%$ the investment received, PP 5.13 month $<5$ years then the investment received, NPV 41,682,000 > 0 then received investments, PI 11.69> 1 then received investments. From research done then capital budgeting can be used as a decisionmaking tool investment fixed assets on the MSMes Serabi Surakarta to anticipate long-term losses.
\end{abstract}

Keywords: MSMes, Capital Budgeting, Investment Decisions, Fixed Assets

\begin{abstract}
Abstrak
Investasi yang baik harus melalui analisis keputusan untuk mengetahui usaha yang dilakukan akan mendapatkan keuntungan atau tidak. Untuk menghindari kerugian yang diterima investor, maka investor harus mengetahui usulan investasinya dengan risiko jangka panjang yang akan diterima. Tujuan Penelitian ini adalah untuk menganalisa kelayakan investasi aktiva tetap berupa penggantian aktiva tetap yang lama dengan aktiva tetap yang baru pada UMKM Serabi di Surakarta, Jawa Tengah dengan menggunakan teknik Capital Budgeting. Metode penelitian ini adalah metode deskripsi dengan pendekatan kuantitatif. Analisis data menggunakan laporan keuangan terbaru untuk menghitung ARR, PP, NPV, dan PI. Dari hasil analisis data diperoleh hasil ARR sebesar 126.6\%> 20\% maka investasi diterima, PP sebesar 5.13 bulan $<5$ tahun maka investasi diterima, NPV sebesar $41.682 .000>0$ maka investasi diterima, PI sebesar $11.69>1$ maka investasi diterima. Dari penelitian yang dilakukan maka capital budgeting dapat dipakai sebagai alat pengambilan keputusan investasi aktiva tetap pada UMKM Serabi Surakarta untuk mengantisipasi kerugian jangka panjang.
\end{abstract}

Kata kunci : UMKM, Capital Budgeting, Keputusan Investasi, Aktiva Tetap

\section{PENDAHULUAN}

Modal merupakan hak residual atas aktiva perusahaan setelah dikurangi semua kewajiban. Modal merupakan sumber dana yang dibutuhkan perusahaan dalam menjalankan kegiatan operasional perusahaannya. Penggunaan modal yang dimiliki perusahaan harus dikelola dengan optimal sehingga memberikan hasil yang menguntungkan perusahaan. Sehingga penggunaan modal membutuhkan penganggaran yang tepat sebelum direalisasikan dalam kegiatan perusahaan.

Kelayakan investasi perlu dianalisis untuk mengetahui usaha yang dilakukan akan mendapatkan keuntungan atau tidak. Untuk menghindari kerugian yang diterima investor, maka investor harus mengetahui usulan investasinya dengan risiko jangka panjang yang akan diterima. Apabila risiko tersebut terlalu besar atau menimbulkan kerugian yang besar maka investor tidak akan melanjutkan investasinya. Risiko yang dihadapi adalah tingkat pengembalian modal yang ditanamkan dalam jangka panjang. Menghindari risiko tersebut perlu dilakukan analisis dan perhitungan yang matang. Analisis proses perencanaan dan pengambilan keputusan investasi aktiva tetap dapat dilakukan dengan teknik perhitungan penganggaran modal (capital budgeting). 
Mbabazize (2014) menjelaskan bahwa "Capital budgeting involves how resources should be allocated in the firm in order to maximize the shareholders' wealth capital budgeting decisions involves commitment of large amounts of money in a given project, and such decisions are hard to reverse without disturbing the organization economically and financially". Sedangkan Viviers \& Cohen (2011) mengemukakan penganggaran modal adalah proses menganalisis peluang investasi di aset jangka panjang yang diharapkan untuk menghasilkan manfaat bagi lebih dari satu tahun. Menurut Khamees (2010) Capital budgeting adalah proses menggunakan dana untuk mengakuisisi operasional aset yang membantu perusahaan untuk mendapatkan pendapatan masa depan.

Dalam Pengganggaran modal mencakup seberapa besar sumber daya yang dimiliki perusahaan yang akan dialokasikan dalam rangka memaksimalkan keuntungan melalui keputusan investasi yang tepat. Sehingga dapat dikatakan bahwa dalam penganggaran modal terdapat rencana yang akan dilaksanakan pada masa mendatang.

Pengangaran modal berperan penting dalam keberhasilan perusahaan, selain itu perencanaan kegiatan operasional perusahaan juga memiliki implikasi terhadap keberhasilan perusahaan. Analisa capital budgeting dilakukan dengan beberapa teknik yaitu Average Rate of Return (ARR), jangka waktu pengembalian (Payback Pariod), Net Present Value (NPV) dan Profitabillity Index (PI).

ARR adalah penilaian proyek investasi yang memfokuskan pada kontribusi suatu investasi pada laba bersih akuntansi atau pendapatan setelah pajak atau net income (Arsyad, 2012). PP adalah waktu yang dibutuhkan untuk dapat menutup kembali pengeluaran investasi semula dengan menggunakan aliran kas (proceeds) atau jumlah periode yang menunjukkan berapa lama dana yang diinvestasikan akan bisa kembali (Al-Ani, 2015) . NPV adalah kelebihan nilai sekarang aliran kas masuk terhadap nilai sekarang aliran kas keluar atau selisih antara present value dari investasi dengan nilai sekarang dari penerimaan-penerimaan kas bersih dimasa yang akan datang (Žižlavský, 2014). PI adalah perbandingan antara nilai-nilai sekarang dari penerimaan-penerimaan kas bersih di masa depan dengan nilai sekarang dari investasi awal (Gurau, 2012).

Menurut Rigopoulos (2015) bahwa keputusan penganggaran modal adalah yang paling penting untuk kinerja perusahaan dan prospek masa depan. Beberapa studi terdahulu telah menunjukkan pentingnya praktek penganggaran modal sebagai alat untuk mengevaluasi kelayakan kemungkinan investasi di dunia usaha (Maroyi \& Poll, 2012). Olawale (Maroyi \& Poll, 2012) menggambarkan penganggaran modal sebagai suatu formulasi dan pembiayaan rencana jangka panjang untuk investasi.

Permasalahan yang dihadapi Perusahaan Serabi yaitu besarnya permintaan konsumen terhadap produk serabi perusahaan tersebut serta mengantisipasi kerugian ketika terdapat kompetitor usaha yang sama. Hal tersebut perlu adanya usaha dari investor untuk mengantisipasi hal tersebut (Kengatharan, 2016). Perusahaan serabi membutuhkan pergantian aktiva tetap yang lama dengan aktiva tetap yang baru. Maka, Perusahaan Serabi Surakarta memerlukan analisa yang baik untuk mengambil keputusan investasi tetap tersebut.

Menurut Tandelilin (2010); Sofiaty, Rahayu \& Endang (2015) mengemukakan bahwa investasi merupakan komiten untuk menanamkan sejumlah dana pada saat ini untuk mendapatkan keuntungan dimasa yang akan datang. Keputusan investasi yang tepat dapat menghasilkan hasil yang spektakuler dalam hal keuntungan tetapi keputusan keliru dan tidak benar dapat membahayakan kelangsungan hidup dari bisnis (Singh, Jain \& Yadav, 2012).

Ada 2 jenis investasi aktiva tetap, diantaranya yaitu aktiva tetap berwujud dan aktiva tetap tidak berwujud (Hery dan Lekok, 2011). Aktiva tetap berwujud adalah standar dasar yang mengatur aturan akuntansi, penilaian dan presentasi dari perbaikan asset tetap (Lech \& Kamieniecka, 2014). Aset tetap tidak berwujud adalah Aktiva tetap tidak berwujud adalah aset yang akan digunakan lebih dari satu tahun, telah tidak ada substansi fisik, dapat diidentifikasi dan non-keuangan (Esen \& Perek, 2016). 
Seorang investor yang ingin mengganti atau menambah aktiva tetap harus melakukan perhitungan yang matang. Maka dengan metode-metode analisis tersebut, perusahaan akan dapat mengetahui jangka pengembalian modal yang telah ditanam pada perusahaan tersebut dan perusahaan dapat mengambil keputusan apabila terjadi risiko yang akan dihadapi. Oleh karena kebutuhan tersebut, maka diperlukan analisis yang matang guna mengambil keputusan yang tepat terhadap perencanaan modal yang akan ditanamkan pada suatu perusahaan.

\section{METODE PENELITIAN}

Penelitian ini adalah metode deskripsi dengan pendekatan kuantitatif, karena penelitian ini disajikan dengan angka-angka. Penelitian ini menggunakan ex post facto. Menurut Sugiyono (2009) bahwa Ex Post Facto adalah suatu penelitian yang dilakukan untuk meneliti peristiwa yang telah terjadi dan kemudian meruntut kebelakang untuk mengetahui faktor-faktor yang menimbukan kejadian tersebut.

\section{A. Tempat Penelitian}

Tempat penelitian yang dipilih adalah UKM Serabi Gulung yang beralamatkan di Jl. Sampangan no 31, Semanggi, Pasar Kliwon, Kota Surakarta, Jawa Tengah.

\section{B. Waktu Penelitian}

Waktu penelitian dilakukan untuk memperoleh data dan informasi yang akurat. Maka, penelitian dilakukan dari bulan Juli sampai dengan September 2017.

\section{Fokus Penelitian}

Penelitian ini berfokus pada penerapan analisis investasi sebagai alat untuk pengambilan keputusan investasi dalam aktiva tetap ditinjau dari aspek keuangan. Hanya aspek keuangan yang diteliti karena hanya terfokus pada perencanaan pembiayaan, analisis investasi dan pengambilan keputusan. Pola perhitungan yang digunakan yaitu aliran kas masuk dan depresiasi, serta penilaian investasi.

\section{Sumber Data}

Dalam penelitian ini penulis menggunakan dua sumber data yaitu data primer dan data sekunder. Data Primer adalah data yang diperoleh langsung dari sumbernya, diamati dan dicatat pertama kali oleh peneliti. Data primer ini diperoleh langsung dari keterangan pemilik investastor serabi. Data sekunder adalah data yang diperoleh dari atau berasal bahan kepustakaan. Sumber data sekunder diperoleh dari dokumen-dokumen yang terkait dengan penelitian yang ada di kajian kepustakaan.

\section{HASIL DAN PEMBAHASAN}

\section{A. Gambaran Umum}

Modal Awal sebesar Rp. 5.000.000 untuk membeli peralatan dan perlengkapan usaha. Setelah beberapa tahun kemudian mempunyai keuntungan yang memadai untuk berinvestasi pada aktiva tetap yaitu membeli beberapa tungku kompor serabi seharga kurang lebih Rp 3.000.000 estimasi umur ekonomis 5 tahun. Investasi yang dilakukan adalah dengan tabungan pribadi tanpa utang.

\section{B. Perkiraan Aliran Kas Keluar}

Perkiraan aliran kas keluar yaitu Rp.6.000.000. Perkiraan tersebut dipergunakan untuk membeli tungku kompor 2 unit seharga Rp. 3.000.000. Berikut penjelasan pada tabel 1. 
Tabel 1. Estimasi Aliran Kas Keluar

\begin{tabular}{cccc}
\hline Investasi & Harga Satuan $(\mathrm{Rp})$ & Unit & Total Cost $(\mathrm{Rp})$ \\
\hline Tungku kompor & 3.000 .000 & 2 & 6.000 .000 \\
\hline
\end{tabular}

\section{Perkiraan Aliran Kas Masuk}

Tungku serabi diperkirakan dalam sehari tiap memproduksi 200-250 serabi sehingga untuk pertahun menghasilkan 225 buah kali 360 hari adalah 80.000 buah serabi untuk dua tungku maka diperkirakan 160.000 buah/tahun.

\section{Estimasi Hasil Penjualan dari Investasi Aset Tetap}

Penjualan hasil produksi serabi gulung akan menjadi arus penerimaan (proceed) dalam usaha ini selama bisnis berjalan. Harga jual serabi tiap bijinya adalah Rp 800,00. Berikut dijelaskan pada tabel 2.

\begin{tabular}{cc}
\multicolumn{2}{c}{ Tabel 2. Estimasi Hasil Penjualan } \\
\hline Tahun & Tungku Serabi \\
\hline 1 & 160.000 buah \\
2 & 160.000 buah \\
3 & 160.000 buah \\
4 & 160.000 buah \\
5 & 160.000 buah \\
Jumlah & 800.000 buah \\
\hline
\end{tabular}

\section{E. Analisis Data}

Berdasarkan dari data, maka teknik analisis data metode Capital Budgeting sebagai alat pengambilan keputusan antara lain sebagai berikut:

a) Average Rate of Return (ARR)

Kriteria kelayakan:

1) ARR yang diperoleh lebih besar dari ARR minimi maka proyek dapat dilanjutkan atau diterima.

2) ARR yang diperoleh lebih kecil dari ARR minimum maka proyek tidak dapat dilanjutkan atau proyek ditolak.

ARR yang telah ditentukan adalah $20 \%$, hasil perhitungan ARR:

$$
\begin{aligned}
& \mathrm{ARR}=\frac{\text { Laba bersih setelah pajak tahunan }}{\text { Investasi rata-rata }} \\
& A R R=\frac{\operatorname{Rp} 75.960 .000}{\operatorname{Rp} 6.000 .000} \times 100 \%=126,6 \%
\end{aligned}
$$

Berdasarkan kriteria ARR, maka diperoleh analisa investasi sebesar 126.6\%. Dari hasil tersebut, maka dapat diketahui bahwa ARR > ARR minimum $(126.6 \%>20 \%)$. Maka proyek layak untuk dilaksanakan.

\section{b) Payback Period}

Kriteria Kelayakan:

1) Proyek dapat dijalankan jika masa pemulihan modal investasi lebih pendek dari usia ekonomis. 
2) Proyek ditolak untuk dijalankan jika masa pemulihan modal investasi lebih lama dibandingkan dengan usia ekonomisnya.

Perhitungan:

$$
\begin{gathered}
\mathrm{PP}=\frac{\text { Nilai investasi } \times 1 \text { tahun }}{\text { Kas masuk Bersih }} \\
\mathrm{PP}=\frac{\operatorname{Rp} 6.000 .000}{\operatorname{Rp} 14.032 .000} \times 12=5,13 \text { bulan }
\end{gathered}
$$

Berdasarkan kriteria PP dengan umur ekonomisnya 5 tahun maka diperoleh analisa investasi sebesar 5.13 bulan. Dari hasil tersebut dapat diketahui bahwa proyek dapat dilaksanakan karena pemulihan modal investasi lebih kecil dibandikan dengan umur ekonomis aktiva tetap ( 5.13 bulan $<5$ tahun).

\section{c) Net Present Value (NPV)}

Kriteria kelayakan:

1) Proyek diterima jika NPV bertanda positif (lebih dari 0)

2) Proyek ditolak jika NPV bertanda negatif (kurang dari 0)

Perhitungan:

Tabel 3. Net Present Value (NPV)

\begin{tabular}{cccc}
\hline Tahun & Proceed & DF $(20 \%)$ & Proceed NPV \\
\hline 1 & Rp. 14.032.0000 & 0,83 & Rp 11.693.000 \\
2 & Rp. 14.032.0000 & 0,69 & Rp 9.744.000 \\
3 & Rp. 14.032.0000 & 0,57 & Rp 8.120.000 \\
4 & Rp. 14.032.0000 & 0,48 & Rp 6.767.000 \\
5 & Rp. 14.032.0000 & 0,40 & Rp 5.639.000 \\
Nilai Buku & Rp 200.000 & 0,40 & Rp 80.000 \\
& PV dari Proceed & & Rp 47.682.000 \\
& PV dari Outlay & & Rp 6.000.000 \\
& NPV & & Rp 41.682.000 \\
\hline
\end{tabular}

Berdasarkan kriteria NPV maka diperoleh analisa intvestasi sebesar Rp. 41.682.000. Dari hasil tersebut maka investasi tersebut layak dilaksanakan karena NPV bertanda positif (41.682.000>0).

\section{d) Profitability Index (PI)}

Kriteria kelayakan:

a) Selama PI lebih besar dari 1 maka usulan proyek dapat diterima.

b) Selama PI lebih kecil dari 1 maka usulan proyek harus ditolak.

Perhitungan:

$$
\begin{gathered}
\text { PI }=\frac{\text { PV Kas Masuk }}{\text { PV Kas Keluar }} \\
P I=\frac{\text { Rp } 70.160 .000}{\operatorname{Rp~} 6.000 .000}=11,69
\end{gathered}
$$

Berdasarkan kriteria PI maka diperoleh analisa investasi sebesar $11.69>1$. Dari hasil tersebut maka investasi tersebut layak untuk dilaksanakan karena memenuhi kriteria $(11.69>1)$. 


\section{F. Intepretasi Hasil Penelitian}

Intepretasi hasil penelitian merupakan hasil akhir dari peelitian yang akan dijelaskan pada tabel 4.

Tabel 4. Hasil Penelitian

\begin{tabular}{lllc}
\hline No & Metode & \multicolumn{1}{c}{ Hasil } & Keputusan \\
\hline 1 & ARR & $126,6 \%>20 \%$ & diterima \\
2 & PP & 5.13 Bulan $<5$ Tahun & diterima \\
3 & NPV & $41.682 .000>0$ & diterima \\
4 & PI & $11.69>1$ & diterima \\
\hline
\end{tabular}

Dari tabel 4 dapat diketahui bahwa metode Average Rate of Return (ARR), Payback Period (PP), Net Present Value (NPV) dan Profitability Index (PI) memberikan keputusan diterima. Artinya perusahaan serabi Surakarta dapat melakukan investasi aktiva tetap sesuai dengan perencanaan.

\section{SIMPULAN}

Berdasarkan perhitungan dan analisis hasil penelitian, maka dapat disimpulkan sebagai berikut:

a) Berdasarkan kriteria Average Rate of Return (ARR) maka diperoleh hasil 126.6\%. Dari hasil tersebut maka investasi tersebut layak untuk dilaksanakan karena memenuhi kriteria ARR yang diperoleh lebih besar dari ARR minimum (126.6 \% > 20\%).

b) Berdasarkan kriteria Payback Period (PP) maka diperoleh hasil 5.13 bulan. Dari hasil tersebut maka investasi tersebut layak untuk dilaksanakan karena memenuhi kriteria pemulihan modal investasi lebih kecil dari umur ekonomis aktiva tetap (5.13 bulan $<5$ tahun).

c) Berdasarkan kriteria Net Present Value (NPV) maka diperoleh hasil Rp. 41.682.000. Dari hasil tersebut maka investasi tersebut layak untuk dilaksanakan karena memenuhi kriteria NPV bernilai positif (Rp. 41.682.000).

d) Berdasarkan kriteria Profitability Index (PI) maka diperoleh hasil 11.69. Dari hasil tersebut maka investasi tersebut layak untuk dilaksanakan karena memenuhi kriteria PI lebih besar dari $1(11.69>1)$.

Berdasarkan kesimpulan penelitian, maka investor dapat melakukan investasi aktiva tetap untuk memperoleh keuntungan. Hal tersebut didasarkan pada temuan harga Average Rate of Return (ARR), Payback Period (PP), Net Present Value (NPV) dan Profitability Index (PI) yang memenuhi syarat pengambilan keputusan.

\section{DAFTAR PUSTAKA}

Al-Ani, M. K. (2015). A Strategic Framework to Use Payback Period in Evaluating the Capital Budgeting in Energy and Oil and Gas Sectors in Oman, International Journal of Economics and Financial, 5(2) pp. 469-475.

Arsyad, A. (2012). Net Present Value is better than Internal Rate of Return, Interdisciplinary Journal of Contemporary Research In Business, 4(8), pp. 211-219.

Esen, O. M. \& Perek, A. A. (2016). The Revaluation Model and Its Effects on Financial Statements: An Examination on Bist 100 Companies. Bilgi Ekonomisi ve Yönetimi Dergisi.

Gurau, M. A. (2012). The Use Of Profitability Index In Economic Evaluation of Industrial Investment Projects, Proceedings in Manufacturing Systems, 7(1), pp. 55-58.

Hery \& Lekok, W. (2011). Akuntansi Keuangan Menengah 2, Ed.1. Jakarta: Bumi Aksara.

Kengatharan, L. (2016). Capital Budgeting Theory and Practice: A Review and Agenda for Future Research. Applied Economics and Finance, 2 (3), pp. 15-38.

Khamees, B. A. (2010). Capital budgeting practices in the jordanian industrial corporations. International Journal of Commerce and Management, 20(1). pp. 49-63. 
Lech, M. \& Kamieniecka, M. (2014). Valuation of Tangible Fixed Assets at the Moment ff Transition to the IFRS/IAS (BASED ON KGHM JSC.). Management, Knowledge and Learning.

Maroyi, V., \& Poll, F. M. V. D. (2012). A survey of capital budgeting techniques used by listed mining companies in South Africa. African Journal of Business Management. 6 (32), pp. 9279-9292.

Mbabazize, P. M., \& Daniel, T. (2014). Capital Budgeting Practices In Developing Countries: A Case Of Rwanda. Research journali's Journal of Finance. 2(3) pp. 1-19.

Rigopoulos, G. (2015). A review on real options utilization in capital budgeting practice. International Journal of Information, Business and Management. 7(2). pp. 1-16.

Singh, S., Jain, P. K., \& Yadav, S. S. (2012). Capital budgeting decisions: Evidence from India. Journal of Advances in Management Research. 9 (1). pp. 96 - 112.

Sofiyati, P., Rahayu, S. M \& Endang, W. I. (2015). Analisis Capital Budgeting Sebagai Sarana Pengambilan Keputusan Investasi Aset Tetap. Jurnal Administrasi Bisnis. Vol. 25, pp. 110 .

Sugiyono. (2009). Metode Penelitian Bisnis (Penedekatan Kuantitatif, Kualitatif dan R\&D). Bandung: Alfabeta.

Tendelilin, E. (2010). Portofolio Investasi Teori dan Aplikasi. Edisi Pertama. Yogyakarta: Kanisius.

Viviers, S., \& Cohen, H. (2011). Perspectives on capital budgetingin the south african motor manufacturing industry. Meditari Accountancy Research,19(1). pp.75-93.

Žižlavský, O. (2014). Net Present Value Approach: Method for Economic Assessment of Innovation Projects, Procedia - Social and Behavioral Sciences, 156. pp. 506-512. 